Review Article

\title{
Adrenal Insufficiency in Coronavirus Disease 2019 (COVID-19)-Infected Patients without Preexisting Adrenal Diseases: A Systematic Literature Review
}

\author{
Mehrbod Vakhshoori $\left(\mathbb{D},{ }^{1}\right.$ Maryam Heidarpour ${ }^{(D)},{ }^{2}$ Niloofar Bondariyan $\left(\mathbb{D},{ }^{3}\right.$ \\ Niyousha Sadeghpour $\left(\mathbb{1},{ }^{1}\right.$ and Zohreh Mousavi (i) ${ }^{4}$ \\ ${ }^{1}$ Heart Failure Research Center, Isfahan Cardiovascular Research Institute, Isfahan University of Medical Sciences, Isfahan, Iran \\ ${ }^{2}$ Isfahan Endocrine and Metabolism Research Center, Isfahan University of Medical Sciences, Isfahan, Iran \\ ${ }^{3}$ Department of Clinical Pharmacy, School of Pharmacy, Shiraz University of Medical Sciences, Shiraz, Iran \\ ${ }^{4}$ Metabolic Syndrome Research Center, Mashhad University of Medical Sciences, Mashhad, Iran
}

Correspondence should be addressed to Maryam Heidarpour; heidarpourmaryam110@gmail.com

Received 16 June 2021; Accepted 27 August 2021; Published 15 September 2021

Academic Editor: Henrik Falhammar

Copyright (C) 2021 Mehrbod Vakhshoori et al. This is an open access article distributed under the Creative Commons Attribution License, which permits unrestricted use, distribution, and reproduction in any medium, provided the original work is properly cited.

\begin{abstract}
Background. Coronavirus disease 2019 (COVID-19) manifestations varied completely from its time of emergence. However, the assessment of adrenal insufficiency (AI) in this pandemic is lacking. In this review, we aimed to evaluate the status of AI among COVID-19-infected individuals. Methods. A systematic literature screening in PubMed/MEDLINE, Scopus, and Web of Science was performed until May 23, 2021. We collected relevant published peer-reviewed studies that reported AI occurrence in patients who suffered from COVID-19. Results. A total of 10 records (cross-sectional studies: 3, $N=256$, males: 176 (68.7\%), and case reports: $7, N=7$, males: 4 (57.1\%)) were recruited. The age spectrum ranged from 22 to 96 years. AI was diagnosed with laboratory assessment or radiologic findings. The AI prevalence ranged from $3.1 \%$ to as high as $64.3 \%$ in different studies. Except for one patient, all other patients were discharged in stable conditions in published case reports. Conclusion. This review indicates that AI occurrence in the COVID-19 pandemic seems quite probable; however, the extent and type (primary, secondary, and functional) need to be clarified yet. Appropriate early diagnostic and therapeutic interventions should be done, especially in critically ill patients, to prevent lethal outcomes.
\end{abstract}

\section{Introduction}

Coronaviridae family is a positively charged enveloped singlestranded RNA virus [1]. This family consists of three main members, including severe acute respiratory syndrome (SARS), Middle East respiratory syndrome (MERS), and Coronavirus Disease 2019 (COVID-19) [2-4]. The latter was first diagnosed in Wuhan, China, and due to its rapid spread all over the globe, the World Health Organization (WHO) declared COVID-19 as a worldwide pandemic on March 13, 2020 [5].

Till now, as in May 24, 2021, more than 166 million persons are infected with this highly contagious virus, and more than 3 million patients were deceased in this regard
[6]. From the beginning of the emergence of COVID-19, most patients presented with pulmonary complaints including cough, fever, dyspnea, and respiratory distress, but this virus is not solely invading one particular tissue, and all other vital organs, including the heart, central nervous system, liver, and kidneys could also get involved [7-12]. In addition to mentioned common organs, this infection could be presented with rare manifestations, including rhabdomyolysis, hypocalcemia, and diabetic ketoacidosis $[13,14]$. One probable explanation for this widespread involvement might be due to angiotensin-converting enzyme 2 (ACE2) receptors presented in other organs, in addition to the respiratory tissues [15]. The endocrine system, especially 
adrenal glands, might also be vulnerable during COVID-19 despite less investigation [16]. The involvement of these organs might lead to a catastrophic outcome. Till now, some case reports have been published in patients who experienced adrenal insufficiency (AI) in the context of COVID-19, but a thorough investigation in literature seems required $[17,18]$.

In this review, we aimed to evaluate the proportion of $\mathrm{AI}$ among COVID-19-infected patients.

\section{Materials and Methods}

2.1. Study Protocol and Registration. This review was conducted in the context of Preferred Reporting Items for Systematic Reviews and Meta-Analysis (PRISMA) [19]. We also registered the current research in the International Prospective Register of Systematic Reviews (PROSPERO) with registration ID of CRD42021255298.

2.2. Search Strategy. The three most common medical databases, including PubMed/MEDLINE, Scopus, and Web of Science, were screened to gather relevant records. The following search strategy was used with no time and language limitations in all aforementioned electronic databases: ("adrenal insufficiency" OR "adrenal failure” OR "adrenal injury” OR “adrenal damage” OR "adrenal" " OR “Addison's disease" OR "Addison*”) AND ("coronavirus" OR "covid19” OR "SARS-CoV-2” OR “2019-nCoV” OR "novel coronavirus" OR "nCoV” OR “coronavirus covid-19”).

2.3. Inclusion and Exclusion Criteria. All published peerreviewed studies (case reports, case series, cross-sectional, cohort, case-control, and review studies) investigating AI in patients with documented COVID-19 infection were assessed. Animal studies or any records with incomplete desired information or non-peer-reviewed articles were excluded.

2.4. Selection Process. Two reviewers screened the three previously mentioned electronic databases with a predefined search strategy. In terms of any relevant title or abstract, the full texts were obtained for further assessment. We only counted a single article in terms of duplication. Figure 1 shows the flow diagram of the current review.

2.5. Data Extraction. Data including the first author's name, publication date, study location, and design, sample size, age (mean \pm standard deviation or median (interquartile range or ranges), as reported), sex (male/female), presenting symptoms, AI assessment (laboratory data or radiographic findings), AI types (primary/central), and frequency of AI (\%) were extracted based on study designs. Another researcher evaluated the whole process, and the consensus was made among all authors in terms of any discrepancies.

2.6. Quality and Risk of Bias Assessment. Assessment of multiple systematic reviews (AMSTAR) and critical appraisal tool (AXIS tool) were used for evaluating the quality of systematic reviews and cross-sectional studies, respectively $[20,21]$. In order to assess case reports/series, the Joanna Briggs Institute (JBI) critical appraisal checklist was utilized [22]. We also evaluated the quality of case-control studies using the National Institutes of Health (NIH) quality assessment tool [23].

2.7. Data Synthesis and Statistical Analysis. Due to the small number of heterogeneous observational studies and some published case reports, we could not conduct a meta-analysis, and a narrative data synthesis was performed.

\section{Results}

We found 809 records in all predefined databases. After removing duplicates and implementing inclusion and exclusion criteria, 10 articles (cross-sectional studies: 3, case reports: 7) were enrolled for the current review (Figure 1). AI was defined based on laboratory data, computed tomography $(\mathrm{CT})$ results, or a combination of both methods $[17,18,24,25]$. A summary of included studies based on their designs is provided in Tables 1 and 2. Quality and risk of bias assessment of recruited records are shown in the supplementary material (Tables S1 and S2).

3.1. Cross-Sectional Studies. Three studies on 256 patients were performed to assess the proportion of AI among COVID-19-infected patients. Alzahrani et al. recruited 28 consecutive patients with a median age of 45.5 (range: 25,69 ) years and evaluated morning blood cortisol and adrenocorticotropic hormone (ACTH). The median cortisol and ACTH means were 196 (range: 31, 587) nmol/l and 18.5 (range: 4, 38) ng/l, respectively. They also measured cortisol for the second time (3-5 days after hospitalization) on 20 patients. They found that 2 (10\%), 6 (30\%), and $9(45 \%)$ enrolled participants had cortisol levels of less than 100, 200, and $300 \mathrm{nmol} / \mathrm{l}$, respectively. ACTH was not measured for the $2^{\text {nd }}$ time. Fifteen patients were tested for the third time 8-11 days after admission with median cortisol and ACTH of 238 (range: 57, 594) nmol/l and $16.5(3.1,50.2) \mathrm{ng} / \mathrm{dl}$, respectively. Nine (60\%) participants showed cortisol means of $<300 \mathrm{nmol} / \mathrm{l}$. Furthermore, an ACTH level of less than $30 \mathrm{ng} / \mathrm{dl}$ was observed among 10 (66.6\%) subjects. They finally reported that adrenocortical response during COVID-19 infection might be interrupted, and patients might suffer from central AI [25]. Leyendecker and colleagues recruited 219 patients with moderate to severe COVID-19 infection from March 9 to April 10, 2020, and retrospectively assessed their adrenal glands through triage CT scans to evaluate the incidence of acute adrenal infarction. Enlargement of at least one gland plus fat stranding in suprarenal location was defined as acute adrenal infarction. 51 (23\%) subjects (males: 36 (71\%), age: $67 \pm 11$ years) were revealed as having acute adrenal infarction based on their definitions. AI in this group was diagnosed based on biological data in 4 (7.8\%) subjects. 


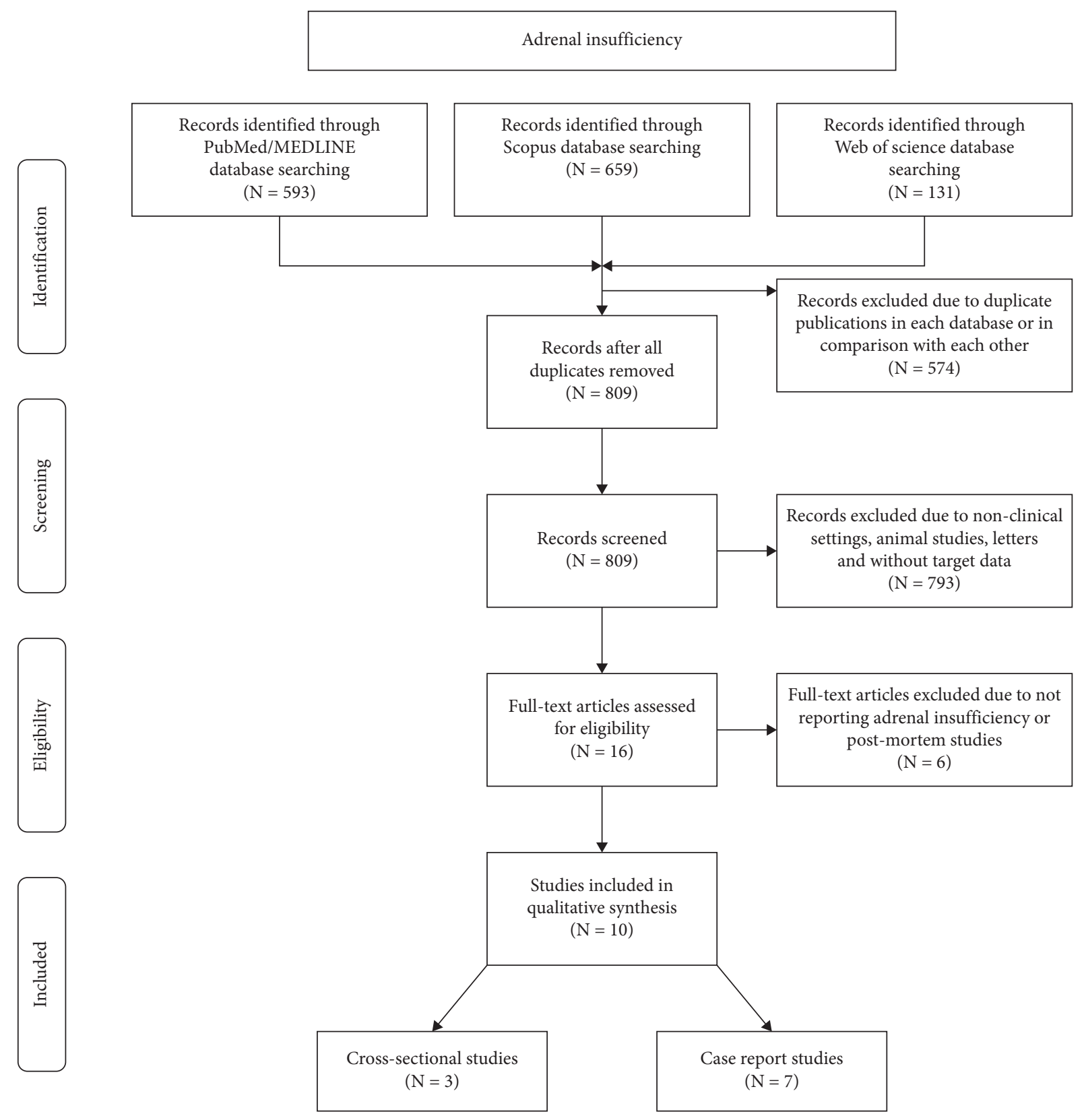

FIgURE 1: Flow diagram of current review.

The frequency of $\mathrm{AI}$ in patients with no presentation of acute adrenal infarction on CT findings was $3(1.7 \%)$, with an overall prevalence of $3.1 \%$ ( 7 out of 219 cases). They also suggested that these adrenal radiographic findings might be associated with a higher intensive care unit admission rate and longer hospital stay in COVID-19 patients [26]. Mao et al. recruited 9 COVID-19-infected patients and 12 non-COVID-19 patients in critical status and assessed the differences in plasma cortisol levels between these two groups. They found that cortisol was significantly lower among COVID-19 patients with severe disease $(P<0.01)$. Half of the non-COVID-19 subjects had elevated cortisol levels compared to $66.6 \%$ of patients in the COVID-19 group who showed cortisol means of $<10 \mu \mathrm{g} / \mathrm{dl}$, which had the required criteria for diagnosis of functional AI, named critical illness-related corticosteroid insufficiency (CIRCI) [27].

3.2. Case Report Studies. Seven records reported AI occurrence during COVID-19 infection in 7 patients. The ages ranged from 44 to 70 years (males: 4). Evaluation of AI was done through CT findings, laboratory profiles, or both in 2 $[24,28], 3[17,18,31]$, and $2[29,30]$ patients, respectively. Only one patient died [28], and all 6 others were discharged in stable condition with appropriate medical treatment [17, 18, 24, 29-31]. 2 patients were followed up after hospital discharge with normal status $[24,29]$. However, two other subjects failed to attend follow-up visits $[17,31]$. The followup data of two patients were not available $[18,30]$. 


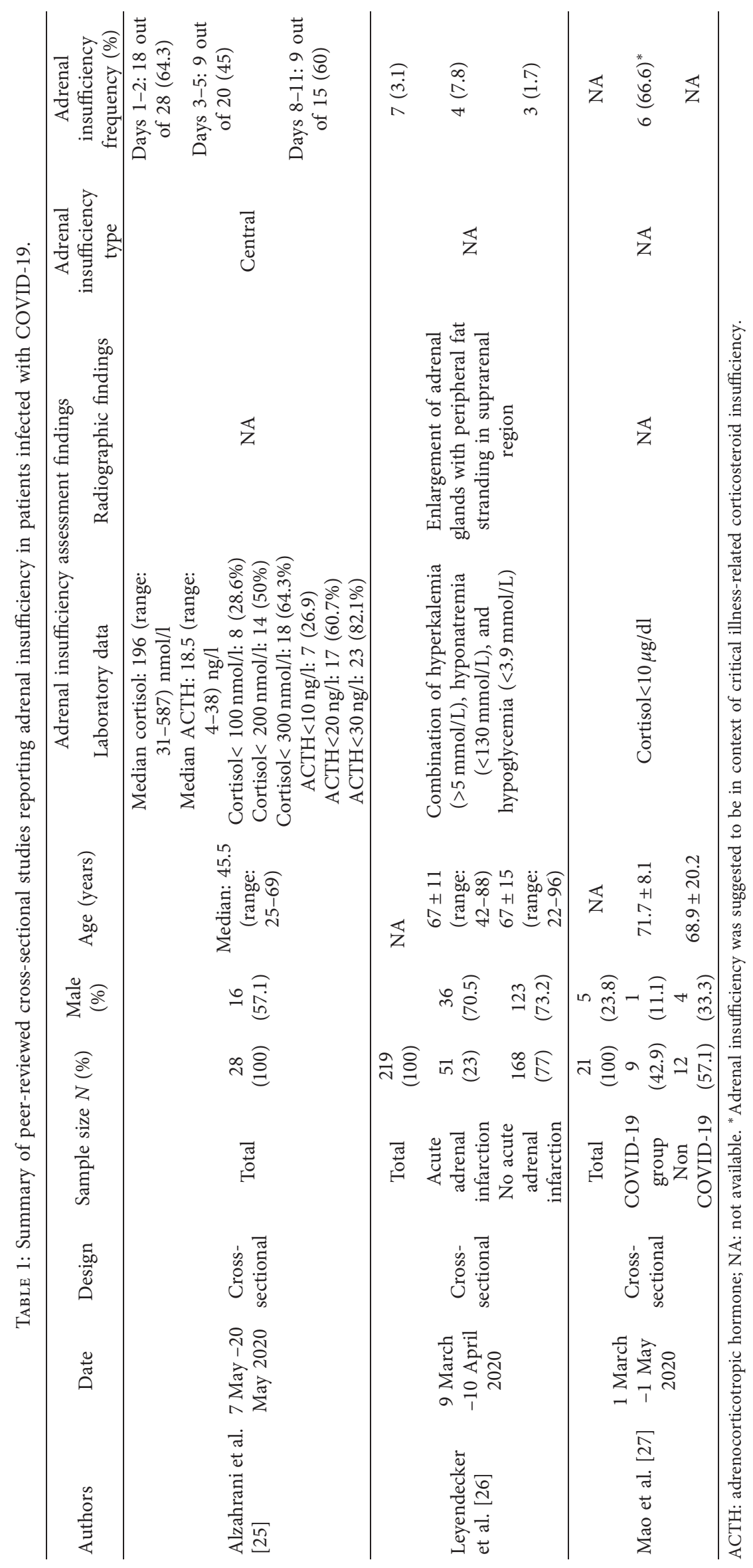


TABLE 2: Summary of peer-reviewed case report studies reporting adrenal insufficiency in patients infected with COVID-19.

\begin{tabular}{|c|c|c|c|c|c|c|c|c|c|}
\hline \multirow{2}{*}{ Authors } & \multirow{2}{*}{$\begin{array}{l}\text { Sample } \\
\text { size }(N)\end{array}$} & \multirow{2}{*}{ Sex } & \multirow{2}{*}{$\begin{array}{l}\text { Age } \\
\text { (years) }\end{array}$} & \multirow{2}{*}{$\begin{array}{l}\text { Presenting } \\
\text { symptoms }\end{array}$} & \multicolumn{2}{|c|}{$\begin{array}{c}\text { Adrenal insufficiency assessment } \\
\text { findings }\end{array}$} & \multirow{2}{*}{$\begin{array}{c}\text { Adrenal } \\
\text { insufficiency } \\
\text { type }\end{array}$} & \multirow{2}{*}{$\begin{array}{l}\text { Patient } \\
\text { status }\end{array}$} & \multirow{2}{*}{$\begin{array}{l}\text { Follow-up } \\
\text { assessment }\end{array}$} \\
\hline & & & & & $\begin{array}{l}\text { Laboratory } \\
\text { data }\end{array}$ & $\begin{array}{l}\text { Radiographic } \\
\text { findings }\end{array}$ & & & \\
\hline $\begin{array}{l}\text { Alvarez- } \\
\text { Troncoso } \\
\text { et al. [24] }\end{array}$ & 1 & Male & 70 & $\begin{array}{l}\text { Fever, chills, } \\
\text { asthenia, } \\
\text { constipation, } \\
\text { malaise, } \\
\text { weakness, } \\
\text { anorexia, } \\
\text { nausea, } \\
\text { vomiting }\end{array}$ & NA & $\begin{array}{l}\text { Increase in size and } \\
\text { blurring of both } \\
\text { adrenals }\end{array}$ & NA & Discharged & $\begin{array}{c}\text { Cortisol } \\
\text { Basal: } \\
2.1 \mu \mathrm{g} / \mathrm{dl} \\
30 \\
\text { minutes: } \\
2.89 \mu \mathrm{g} / \mathrm{dl} \\
60 \\
\text { minutes: } \\
3.11 \mu \mathrm{g} / \mathrm{dl}\end{array}$ \\
\hline $\begin{array}{l}\text { Elkhouly } \\
\text { et al. [28] }\end{array}$ & 1 & Male & 50 & $\begin{array}{l}\text { Fever, malaise, } \\
\text { shortness of } \\
\text { breath, cough }\end{array}$ & NA & $\begin{array}{c}\text { Bilateral } \\
\text { hyperdense ovoid } \\
\text { suprarenal lesions } \\
\text { with loss of normal } \\
\text { adrenal gland } \\
\text { contour }\end{array}$ & $\mathrm{NA}$ & Death & - \\
\hline $\begin{array}{l}\text { Frankel et al. } \\
{[29]}\end{array}$ & 1 & Female & 66 & $\begin{array}{c}\text { Fever, dyspnea, } \\
\text { nausea, } \\
\text { vomiting, } \\
\text { abdominal pain }\end{array}$ & $\begin{array}{c}\text { Baseline } \\
\text { cortisol< } \\
1 \mu \mathrm{g} / \mathrm{dl} \\
\text { ACTH: } 207 \\
\text { pmol/l } \\
\end{array}$ & $\begin{array}{l}\text { Enlarged and thick } \\
\text { adrenal glands plus } \\
\text { haziness of } \\
\text { surrounding peri- } \\
\text { adrenal fat }\end{array}$ & Primary & Discharged & Stable \\
\hline $\begin{array}{l}\text { Heidarpour } \\
\text { et al. [18] }\end{array}$ & 1 & Male & 51 & $\begin{array}{l}\text { Fever, dyspnea, } \\
\text { cough }\end{array}$ & $\begin{array}{c}\text { Cortisol } \\
\text { Baseline: } \\
56 \mathrm{nmol} / \mathrm{l} \\
30 \text { minutes: } \\
197 \mathrm{nmol} / \mathrm{l} \\
60 \mathrm{minutes} \\
297 \mathrm{nmol} / \mathrm{l} \\
\text { Total } \\
\text { cortisol< } \\
12 \mu \mathrm{g} / \mathrm{dl} \\
\end{array}$ & NA & Primary & Discharged & Lost \\
\hline $\begin{array}{l}\text { Kumar et al. } \\
{[30]}\end{array}$ & 1 & Female & 70 & $\begin{array}{l}\text { Fever, left-sided } \\
\text { chest pain, } \\
\text { cough, dyspnea, } \\
\text { fatigue, } \\
\text { abdominal pain, } \\
\text { vomiting, } \\
\text { diarrhea }\end{array}$ & $\begin{array}{l}\text { Random } \\
\text { cortisol> } \\
300 \mathrm{nmol} / 1\end{array}$ & $\begin{array}{l}\text { Enlarged diffusely } \\
\text { hypoattenuated } \\
\text { adrenal glands with } \\
\text { poor enhancement } \\
\text { and ill-defined } \\
\text { adrenal contours }\end{array}$ & $\mathrm{NA}$ & Discharged & NA \\
\hline $\begin{array}{l}\text { Sheikh et al. } \\
\text { [31] }\end{array}$ & 1 & Female & 44 & $\begin{array}{c}\text { Fever, chills, } \\
\text { malaise, } \\
\text { shortness of } \\
\text { breath, myalgia, } \\
\text { loss of taste }\end{array}$ & $\begin{array}{c}\text { Random } \\
\text { cortisol: } \\
1.1 \mu \mathrm{g} / \mathrm{dl} \text {, } \\
\text { ACTH: } 56 \\
\text { pg/ml }\end{array}$ & NA & Central & Discharged & Lost \\
\hline
\end{tabular}

ACTH: adrenocorticotropic hormone; NA: not available.

\section{Discussion}

This review was conducted to assess reported COVID-19-induced AI in the literature. In addition to several case reports, we found that some observational studies also reported this presentation, and either primary or central AI in the context of COVID-19 is not just a rare manifestation of this pandemic. It seems that the occurrence of this entity is probable in clinical settings, and the implementation of future large-scale studies to assess the exact incidence of AI is mandatory. Since the official declaration of this highly infectious agent, variable presentations in different organs have been reported $[7,8,10-12]$. One of the main mechanisms of multiple tissue involvement might be related to cell entry receptors. ACE2 receptors have been suggested to be expressed by the hypothalamus, pituitary, and adrenal glands. Because of the presence of this receptor as one of the main entry cites, COVID-19 could directly invade mentioned organs resulted in primary or secondary AI incidence [32]. Direct invasion of COVID-19 to adrenal glands has been assessed in postmortem studies. Four autopsy studies evaluated adrenal pathologic findings among deceased subjects from COVID-19. Autopsy analysis in 3 out of 


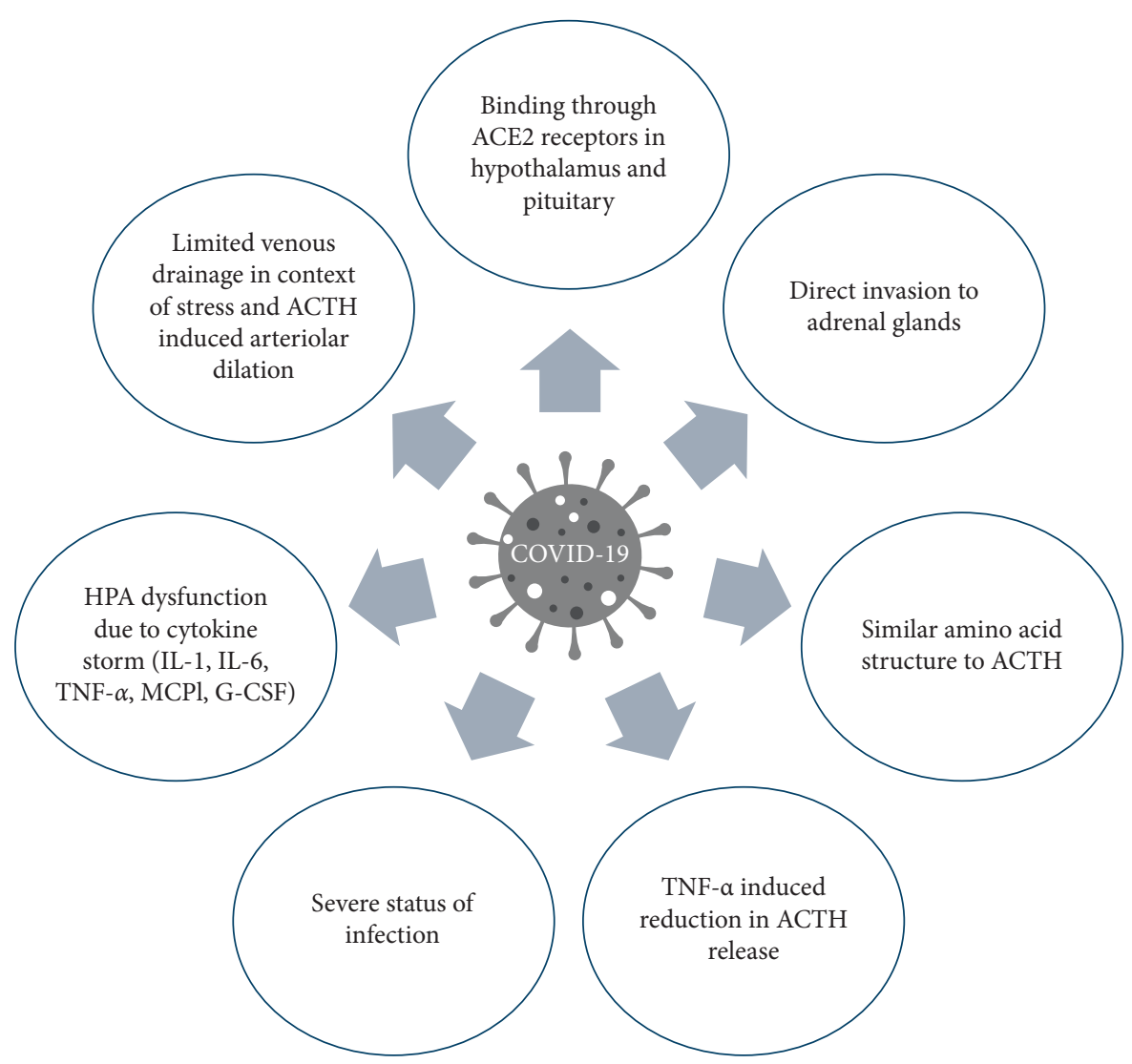

FIGURE 2: Summary of possible pathways of adrenal insufficiency in COVID-19 infection. ACE2: angiotensin-converting enzyme 2, ACTH: adrenocorticotropic hormone, TNF- $\alpha$ : tumor necrosis factor- $\alpha$, IL: interleukin, MCP1: monocyte chemoattractant protein 1, and G-CSF: granulocyte-colony-stimulating factor.

9 dead individuals showed adrenal microinfarction [33]. Iuga et al. assessed adrenal glands pathological slides of 5 postmortem subjects (males: 4) aged 59 to 90. Microscopic findings favored acute fibrinoid necrosis of arterioles in adipose tissue adjacent to adrenals and parenchyma as well as the capsule of adrenal glands [34]. Another autopsy finding performed by Santana and colleagues on 28 deceased adrenal glands showed 12 (46\%) cases had some extents of ischemic and hemorrhagic necrosis, cortical lipid degeneration, and focal adrenalitis [35]. Zinserling and colleagues evaluated 10 autopsy adrenal glands and found that these organs were infiltrated by T-lymphocytes $\left(\mathrm{CD}^{+}\right.$and $\mathrm{CD} 8^{+}$cells) [36].

Regarding other possible AI mechanisms in COVID-19, this virus expresses amino acids similar to human ACTH, and the antibody production by the immune system might impair endogenous ACTH function [32, 37]. Another possibility might be related to cytokines. It has been reported that tumor necrosis factor- $\alpha$ (TNF- $\alpha$ ) reduces ACTH release and decreases its effect on adrenal tissue. Moreover, the pituitary gland is not protected by the blood-brain barrier, and extensive cytokine production (interleukin (IL) 1, IL 6, TNF- $\alpha$, monocyte chemoattractant protein 1 (MCP1), and granulocyte-colony stimulating factor (G-CSF)) during COVID-19 infection might lead to hypothalamic-pituitaryadrenal axis dysfunction [38-41].

The anatomical location of the adrenal gland's vasculatures might be another culprit. These two tiny organs have a network of arterioles that arises from different main arteries, but blood drainage is limited due to a solitary suprarenal vein [42]. The high stress from COVID-19 infection might be a limiting factor for venous drainage due to ACTHinduced arteriolar dilation, leading to vascular stasis and subsequent adrenal damage [43].

Also, the severe status of the disease might be categorized as another explanation in AI incidence. Cholesterol, in the main form of high-density lipoprotein (HDL), is one of the main substrates for cortisol synthesis, and decreased HDL levels in severe disorders might lead to AI [44]. Furthermore, functional AI, named CIRCI, might also result from severe diseases. This functional AI is mainly due to inadequate cortisol secretion for the modulation of inflammatory responses. Multiple mechanisms, including reduced albumin or cortisol binding globulins (CBGs), decreased affinity, and reduced number of adrenal glands cortisol receptors or increased activity of 11- $\beta$ hydroxysteroid dehydrogenase type 2 results in cortisol inactivation are proposed in this regard [45]. Mao et al. reported CIRCI diagnosis in 6 out of 9 critically infected patients with COVID-19 [27]. Long-term studies are required to evaluate whether AI is temporary and related to CIRCI or it would be permanent.

Figure 2 provides a summary of all possible pathways of AI occurrence in the context of COVID-19 infection.

To the best of our knowledge, this review is the first in the literature to assess the status of AI occurrence in the 
COVID-19 era. By the way, several limitations are present. Due to daily reported information in this pandemic, we recruited all relevant records until May 23, 2021. Due to limited numbers of available records with high heterogeneity and a small sample size, we could not conduct a metaanalysis. Therefore, the generalization of our outcomes should be made with caution. Finally, we were unable to assess the frequency of AI based on disease severity.

In conclusion, we found that $\mathrm{AI}$ is a probable disease unrecognized in clinical settings in this COVID-19 pandemic. Therefore, assessing adrenal glands with laboratory or radiographic findings could be performed, especially among critically ill patients.

\section{Abbreviations:}

SARS: $\quad$ Severe acute respiratory syndrome

MERS: $\quad$ Middle East respiratory syndrome

COVID-19: Coronavirus disease 2019

WHO: World Health Organization

ACE2: $\quad$ Angiotensin-converting enzyme 2

AI: $\quad$ Adrenal insufficiency

PRISMA: Preferred Reporting Items for Systematic Reviews and Meta-Analysis

PROSPERO: International Prospective Register of Systematic Reviews

AMSTAR: Assessment of multiple systematic reviews

AXIS: Critical appraisal tool for cross-sectional studies

JBI: Joanna Briggs Institute (JBI)

NIH: $\quad$ National Institutes of Health

CT: $\quad$ Computed tomography

ACTH: Adrenocorticotropic hormone

CIRCI: Critical illness-related corticosteroid insufficiency

TNF- $\alpha$ : $\quad$ Tumor necrosis factor- $\alpha$

IL: Interleukin

MCP1: $\quad$ Monocyte chemoattractant protein 1

G-CSF: Granulocyte-colony-stimulating factor

HDL: $\quad$ High-density lipoprotein

CBG: $\quad$ Cortisol binding globulins.

\section{Data Availability}

The datasets generated during and/or analyzed during the current study are not publicly available due to confidential issues but are available from the corresponding author on reasonable request.

\section{Conflicts of Interest}

The authors declare that they have no conflicts of interest.

\section{Authors' Contributions}

M. V. and M. H. were involved in study concept and design and analysis and interpretation of data. M. V., N. B., and N. S. were involved in acquisition of data. M. V, N. S, and N. B. drafted the manuscript. M. V., M. H., and Z. M. critically revised the manuscript for valuable intellectual content M. H. and Z. M. provided administrative, technical, and material support and supervised the study.

\section{Supplementary Materials}

Table S1: risk of bias assessment of cross-sectional studies. Table S2: risk of bias assessment of case report studies. (Supplementary Materials)

\section{References}

[1] S. G. Siddell, R. Anderson, D. Cavanagh et al., "Coronaviridae," Intervirology, vol. 20, no. 4, pp. 181-189, 1983.

[2] WHO, Summary of Probable SARS Cases with Onset of Illness from 1 November 2002 to 31, WHO, Geneva, Switzerland, 2003.

[3] A. Badawi and S. G. Ryoo, "Prevalence of diabetes in the 2009 influenza A (H1N1) and the Middle East respiratory syndrome coronavirus: a systematic review and meta-analysis," Journal of public health research, vol. 5, no. 3, 2016.

[4] C. Huang, Y. Wang, X. Li et al., "Clinical features of patients infected with 2019 novel coronavirus in Wuhan, China," The lancet, vol. 395, no. 10223, pp. 497-506, 2020.

[5] WHO, Novel Coronavirus (2019-nCoV): situation report, WHO, Geneva, Switzerland, 2020.

[6] WHO, WHO Coronavirus (COVID-19), WHO, Geneva, Switzerlandhttps://covid19.who.int/.

[7] W.-j Guan, Z.-y Ni, Y. Hu, W.-h Liang, C.-q Ou, J.-x He et al., "Clinical characteristics of coronavirus disease 2019 in China," New England Journal of Medicine, vol. 382, no. 18, pp. 1708-1720, 2020.

[8] D. Wang, B. Hu, C. Hu et al., "Clinical characteristics of 138 hospitalized patients with 2019 novel coronavirus-infected pneumonia in wuhan, China," Jama, vol. 323, no. 11, pp. 1061-1069, 2020.

[9] M. Gavriatopoulou, E. Korompoki, D. Fotiou et al., "Organspecific manifestations of COVID-19 infection," Clinical and Experimental Medicine, pp. 1-14, 2020.

[10] M. Madjid, P. Safavi-Naeini, S. D. Solomon, and O. Vardeny, "Potential effects of coronaviruses on the cardiovascular system," JAMA cardiology, vol. 5, no. 7, pp. 831-840, 2020.

[11] M. Vakhshoori, M. Heidarpour, D. Shafie, M. Taheri, N. Rezaei, and N. Sarrafzadegan, "Acute cardiac injury in COVID-19: a systematic review and meta-analysis," Archives of Iranian Medicine, vol. 23, no. 11, pp. 801-812, 2020.

[12] M. Vakhshoori, S. A. Emami, M. Heidarpour, D. Shafie, and M. Mortazavi, "Corona virus disease 2019 (COVID-19) and its effect on renal system, A systematic review and metaanalysis," Iranian journal of kidney diseases, vol. 14, no. 6, pp. 419-438, 2020.

[13] M. Heidarpour, M. Vakhshoori, M. A. Haghighatpanah, L. Ashrafi, F. Khorvash, and B. Iraj, "Rhabdomyolysis plus hypocalcemia and diabetic ketoacidosis as concurrent rare COVID-19 manifestations," Case Reports in Medicine, p. 2021, 2021.

[14] S. G. Khosla, E. S. Nylen, and R. Khosla, "Rhabdomyolysis in patients hospitalized with COVID-19 infection: five case series," Journal of investigative medicine high impact case reports, vol. 8, p. 2324709620984603, 2020.

[15] I. Hamming, W. Timens, M. Bulthuis, A. Lely, G. Navis, and H. van Goor, "Tissue distribution of ACE2 protein, the functional receptor for SARS coronavirus. A first step in understanding SARS pathogenesis," The Journal of Pathology, vol. 203, no. 2, pp. 631-637, 2004. 
[16] A. Siejka and N. Barabutis, "Adrenal insufficiency in the COVID-19 era," American Journal of Physiology-Endocrinology and Metabolism, vol. 320, no. 4, pp. E784-E785, 2021.

[17] M. Hashim, S. Athar, and W. H. Gaba, "New onset adrenal insufficiency in a patient with COVID-19," BMJ Case Reports CP, vol. 14, no. 1, Article ID e237690, 2021.

[18] M. Heidarpour, M. Vakhshoori, S. Abbasi, D. Shafie, and N. Rezaei, "Adrenal insufficiency in coronavirus disease 2019: a case report," Journal of Medical Case Reports, vol. 14, no. 1, pp. 1-4, 2020.

[19] L. A. Stewart, M. Clarke, M. Rovers et al., "Preferred reporting Items for a systematic review and meta-analysis of individual participant data," Jama, vol. 313, no. 16, pp. 1657-1665, 2015.

[20] B. J. Shea, J. M. Grimshaw, G. A. Wells, M. Boers, N. Andersson, C. Hamel et al., "Development of AMSTAR: a measurement tool to assess the methodological quality of systematic reviews," BMC Medical Research Methodology, vol. 7, no. 1, pp. 1-7, 2007.

[21] M. J. Downes, M. L. Brennan, H. C. Williams, and R. S. Dean, "Development of a critical appraisal tool to assess the quality of cross-sectional studies (AXIS)," BMJ open, vol. 6, no. 12, Article ID e011458, 2016.

[22] S. Moola, Z. Munn, C. Tufanaru, E. Aromataris, K. Sears, R. Sfetcu et al., "Chapter 7: systematic reviews of etiology and risk," Joanna Briggs Institute Reviewer's Manual The Joanna Briggs Institute, vol. 5, 2017.

[23] Study Quality Assessment Tools. https://www.nhlbi.nih.gov/ health-topics/study-quality-assessment-tools.

[24] J. Álvarez-Troncoso, M. Zapatero Larrauri, M. D. Montero Vega et al., "Case report: COVID-19 with bilateral adrenal hemorrhage," The American Journal of Tropical Medicine and Hygiene, vol. 103, no. 3, pp. 1156-1157, 2020.

[25] A. S. Alzahrani, N. Mukhtar, A. Aljomaiah et al., "The impact of COVID-19 viral infection on the hypothalamic-pituitary-adrenal axis," Endocrine Practice, vol. 27, no. 2, pp. 83-89, 2021.

[26] P. Leyendecker, S. Ritter, M. Riou et al., "Acute adrenal infarction as an incidental CT finding and a potential prognosis factor in severe SARS-CoV-2 infection: a retrospective cohort analysis on 219 patients," European Radiology, vol. 31, no. 2, pp. 895-900, 2021.

[27] Y. Mao, B. Xu, W. Guan et al., "The adrenal cortex, an underestimated site of SARS-CoV-2 infection," Frontiers in Endocrinology, vol. 11, 2020.

[28] M. M. N. Elkhouly, A. A. Elazzab, and S. S. Moghul, "Bilateral adrenal hemorrhage in a man with severe COVID-19 pneumonia," Radiology Case Reports, vol. 16, no. 6, pp. 1438-1442, 2021.

[29] M. Frankel, I. Feldman, M. Levine et al., "Bilateral adrenal hemorrhage in coronavirus disease 2019 patient: a case report," Journal of Clinical Endocrinology \& Metabolism, vol. 105, no. 12, pp. 3745-3749, 2020.

[30] R. Kumar, T. Guruparan, S. Siddiqi et al., "A case of adrenal infarction in a patient with COVID 19 infection," BJR| case reports, vol. 6, no. 3, p. 20200075, 2020.

[31] A. B. Sheikh, M. A. Javaid, A. A. E. Sheikh, and R. Shekhar, "Central adrenal insufficiency and diabetes insipidus as potential endocrine manifestations of COVID-19 infection: a case report," The Pan African Medical Journal, vol. 38, no. 222, p. 222, 2021.

[32] R. Pal, "COVID-19, hypothalamo-pituitary-adrenal axis and clinical implications," Endocrine, vol. 68, no. 2, pp. 251-252, 2020.

[33] B. Hanley, K. N. Naresh, C. Roufosse et al., "Histopathological findings and viral tropism in UK patients with severe fatal
COVID-19: a post-mortem study," The Lancet Microbe, vol. 1, no. 6, pp. e245-e253, 2020.

[34] A. C. Iuga, C. C. Marboe, M. M. Yilmaz, J. H. Lefkowitch, C. Gauran, and S. M. Lagana, "Adrenal vascular changes in COVID-19 autopsies," Archives of Pathology \& Laboratory Medicine, vol. 144, no. 10, pp. 1159-1160, 2020.

[35] M. F. Santana, M. G. S. Borba, D. C. Baía-da-Silva et al., "Case report: adrenal pathology findings in severe COVID-19: an autopsy study," The American Journal of Tropical Medicine and Hygiene, vol. 103, no. 4, pp. 1604-1607, 2020.

[36] V. A. Zinserling, N. Y. Semenova, A. G. Markov et al., "Inflammatory cell infiltration of adrenals in COVID-19," Hormone and Metabolic Research, vol. 52, no. 9, pp. 639-641, 2020.

[37] R. Wheatland, "Molecular mimicry of ACTH in SARS implications for corticosteroid treatment and prophylaxis," Medical Hypotheses, vol. 63, no. 5, pp. 855-862, 2004.

[38] A. Bateman, A. Singh, T. Kral, and S. Solomon, "The immunehypothalamic-pituitary-adrenal Axis*," Endocrine Reviews, vol. 10, no. 1, pp. 92-112, 1989.

[39] A. Soni, G. M. Pepper, P. M. Wyrwinski et al., "Adrenal insufficiency occurring during septic shock: incidence, outcome, and relationship to peripheral cytokine levels," The American Journal of Medicine, vol. 98, no. 3, pp. 266-271, 1995.

[40] R. Natarajan, S. Ploszaj, R. Horton, and J. Nadler, "Tumor necrosis factor and interleukin-1 are potent inhibitors of angiotensin-II-induced aldosterone synthesis*," Endocrinology, vol. 125, no. 6, pp. 3084-3089, 1989.

[41] J. Guarner, C. D. Paddock, J. Bartlett, and S. R. Zaki, “Adrenal gland hemorrhage in patients with fatal bacterial infections," Modern Pathology, vol. 21, no. 9, pp. 1113-1120, 2008.

[42] B. Fox, "Venous infarction of the adrenal glands," The Journal of Pathology, vol. 119, no. 2, pp. 65-89, 1976.

[43] A. Piccioli, G. Chini, M. Mannelli, and M. Serio, "Bilateral massive adrenal hemorrhage due to sepsis: report of two cases," Journal of Endocrinological Investigation, vol. 17, no. 10, pp. 821-824, 1994.

[44] J.-Y. Chien, J.-S. Jerng, C.-J. Yu, and P.-C. Yang, "Low serum level of high-density lipoprotein cholesterol is a poor prognostic factor for severe sepsis*," Critical Care Medicine, vol. 33, no. 8, pp. 1688-1693, 2005.

[45] D. Annane, S. M. Pastores, B. Rochwerg et al., "Guidelines for the diagnosis and management of critical illness-related corticosteroid insufficiency (CIRCI) in critically ill patients (Part I): society of Critical Care Medicine (SCCM) and European Society of Intensive Care Medicine (ESICM) 2017," Intensive Care Medicine, vol. 43, no. 12, pp. 1751-1763, 2017. 